\title{
Study of Frozen Section Biopsy as Intraoperative Procedure for Oral Squamous Cell Carcinoma in BSMMU
}

\author{
Swapan Kumer Mondoul ${ }^{1}$, Farzana Hakim ${ }^{1}$, Mahmuda Akhter ${ }^{1}$, Shakhawat Hossain ${ }^{1}$, Ashim Ranjan Barua ${ }^{2}$, \\ Motiur Rahman Molla ${ }^{1}$ \\ ${ }^{1}$ Department of Oral \& Maxillofacial Surgery, Faculty of Dentistry, Bangabandhu Sheikh Mujib Medical University, ${ }^{2}$ Department of Pathology, \\ Faculty of Basic Science, Bangabandhu Sheikh Mujib Medical University, Dhaka
}

\begin{abstract}
:
Background: Frozen section biopsy technique often helps a rapid diagnosis of a mass during surgery which in turn may helps a surgeon to know the status of the margins of his resection before closing. Objective: The study was done to achieve tumour free surgical margin after resection of oral squamous cell carcinoma (OSCC). The study also examined to determine positive margins and its relation to tumour size, grade and stage of oral squamous cell carcinoma. Method: This cross sectional study was done in 29 patients of oral sqamous cell carcinoma. Result: One hundred eleven margins of frozen section (FS) biopsy were taken from 29 patients (mean 3.8) for comparing with the permanent sections of the same tissue sample. Among them, one false positive and three false negative were found and an accuracy rate was $96.4 \%$. Out of one hundred eleven margins, 32 (28.8\%) were positive and $79(71.2 \%)$ were negative. In case of $\mathrm{T}_{3}$ and $\mathrm{T}_{4}$ tumour, the number of the positive margins was greater (respectively $27.8 \%$ and $50 \%$ ). In stage III and stage IV cases, the number of positive margins was greater (29.1 and 30\% respectively). Regarding histopathology grading, grade III was the highest (33.3\%). Conclusion: The intra-operative frozen section biopsy plays an important role to achieve tumour free surgical margin in the resection of oral squamous cell carcinoma. In this study, it was also observed that the number of positive margins increased in relation to increased tumour size and tumour stage (cTNM).
\end{abstract}

Key Words: Oral squamous cell carcinoma, Frozen section biopsy, Radiotherapy, Chemotherapy.

[BSMMU J 2009; 2(1): 8-13]

\section{Introduction:}

Biopsies are small sample of tissue taken from a mass or tumour that are examined under a microscope to make a diagnosis. Frozen section biopsy is done per-operatively which facilitate the appropriate excision particularly in cancer surgery. The result of the frozen section biopsy greatly influence the surgeon's intra-operational decision.

The pathologist has to make correct decision in a shorter period of time utilizing all his clinical experience, knowledge and judgment. One should also take into account the limitations of this method, as the patient's life is often dramatically influenced by this report.

With the advancement of a modern reliable FS technique, intra-operative problems could be addressed immediately. Early FS techniques were difficult and demanding and required as much art as science. ${ }^{1}$

Head and neck cancer is a common problem worldwide with an increasing incidence in developing countries. Oral

Address for correspondence: Dr. Swapan Kumer Mondoul, Department of Oral \& Maxillofacial Surgery, Faculty of Dentistry, Bangabandhu Sheikh Mujib Medical University, Dhaka. E-mail: drswapan.omfs@gmail:com Contact: 01716630145 cancer accounts for approximately 30\% of all head and neck cancers and $95 \%$ of these are squamous cell carcinoma. In Bangladesh the number of new cancer cases are about 2,00,000 per year, of which oral cancer represents $20 \% .^{2}$

The rate of oral cancer is increasing day by day. Different institutes and hospitals are giving different treatment options like surgery, radiotherapy and chemotherapy in our country. But the recurrence rate is still high and five years survival rate is not up to the mark. Local recurrence of cancer is usually due to the result of incomplete excision of the lesion. In order to ensure the complete excision and prevent recurrence, one could take the opportunity of frozen section biopsy per-operatively.

Wide excision of the lesion is quite important in cancer surgery. Loree and Strong reported that obtaining a tumour free margin, can eradicate the tumour as well as its microscopic extensions, which ultimately will cause better local control of malignant disease. ${ }^{3}$ Ribeiro et. al mentioned on their study that recurrence most commonly occurs when $1 \mathrm{~cm}$ margin of normal healthy tissue is not achieved around the tumour at the time of resection. ${ }^{4}$ 
Some researchers reported that a margin of 5 to $10 \mathrm{~mm}$ of healthy tissue is generally accepted during surgical excision of oral cancer. ${ }^{5}$ However, resection of the visible and palpable tumour mass including a wide margin does not always result in radical removal of cancer. ${ }^{6,7}$ Despite of wide surgical excision if frozen section analysis shows that the resection margin is not clear of malignant disease, re-excision should be performed and new margin submitted for additional frozen section evaluation until clear margin is obtained. Therefore, frozen section analysis for peroperative margin assessment has become a popular intra-operative guide in the management of oral cancer.

Surgery with per-operative frozen section biopsy to ensure tumour free margin is better than radiotherapy alone or surgery combined with post operative radiotherapy. Because radiotherapy can not ensure the total eradication of squamous cell carcinoma. Post operative radiotherapy not only produces various hazards on the general condition of the patient, but also complicate the primary surgical site.

In a study on surgery vs surgery and radiotherapy, Loree and Strong reported that local recurrence rates in patients with positive margins who underwent radiotherapy were greater than local recurrence rates in comparable patients with negative margins not receiving post operative radiotherapy. ${ }^{3}$ They also mentioned that adjuvant postoperative radiotherapy was not effective to control local recurrence in the presence of positive margins. Resection of involved margins in a secondary surgical procedure is often unacceptable and/or impractical. ${ }^{3,6}$ For this reason, in situations where a positive margin is found (by paraffin preparation), the use of post operative radiotherapy is advocated as early as possible at full therapeutic dosage. So, one can easily understand the importance of frozen section biopsy.

\section{Methods}

This cross sectional study was done in the Department of the Oral and Maxillofacial Surgery and Department of Pathology, BSMMU from January, 2006 to December, 2007. 29 cases of histopathologically diagnosed OSCC patients with or without radiotherapy and/or chemotherapy were selected but patients undergoing palliative surgery were discarded. Size, grade and stage of lesion were recorded.

At least one day before operation the surgeon had to inform the pathology department. Pathological requisition form on which minimum important information of the patient and approximate time for FS are written. After excision, the unfixed fresh specimen was quickly sent for frozen section biopsy to Department of Pathology (Fig.-1).

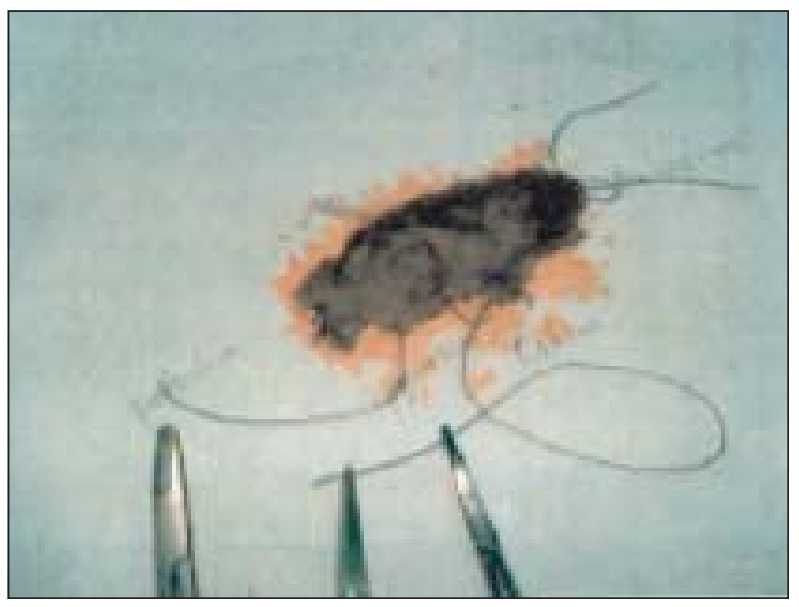

Fig.-1: Tumour (OSSC) with threads.

Blocks taken from different margins were coloured differently to differentiate the margins and the slides were numbered accordingly. The numbers were noted on a paper. The tissue block on holder was then embeded into cryomatrix in the cryostat machine in $-18^{0} \mathrm{c}$ to $-30^{0} \mathrm{c}$ temp. In the cryostat machine (Fig.-2).

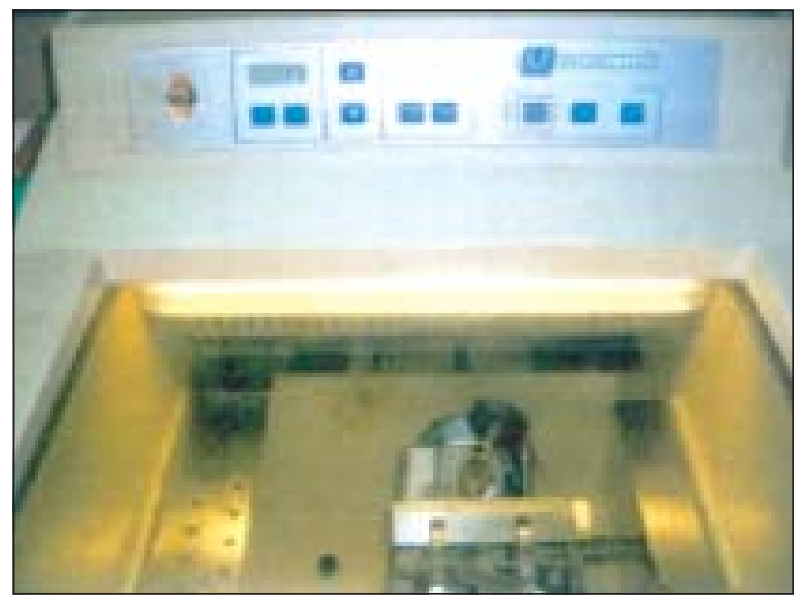

Fig.-2: Cryostat Machine

After 1 to 2 minutes, the embeded tissue and cryomatrix turned frosted white in colour and hard. The tissue block (small specimen) was cut into 5-6 micron thickness by using rotary microtome. The sectioned tissues were picked up, placed in the same numbered slide and was then placed into carnoy's fixative containing coplin jar. The sections were stained by quick haematoxylin and eosin stain.

The sections were examined microscopically (Fig. 3a, 3b, $4 \mathrm{a}, 4 \mathrm{~b})$. Results were recorded on the frozen section request form. FS result was informed to the surgeon. Total 
procedure was completed within about 15-20 minutes. In case of any positive margin, $2^{\text {nd }}$ sample from the positive site of the lesion was sent for further histopathological examination.

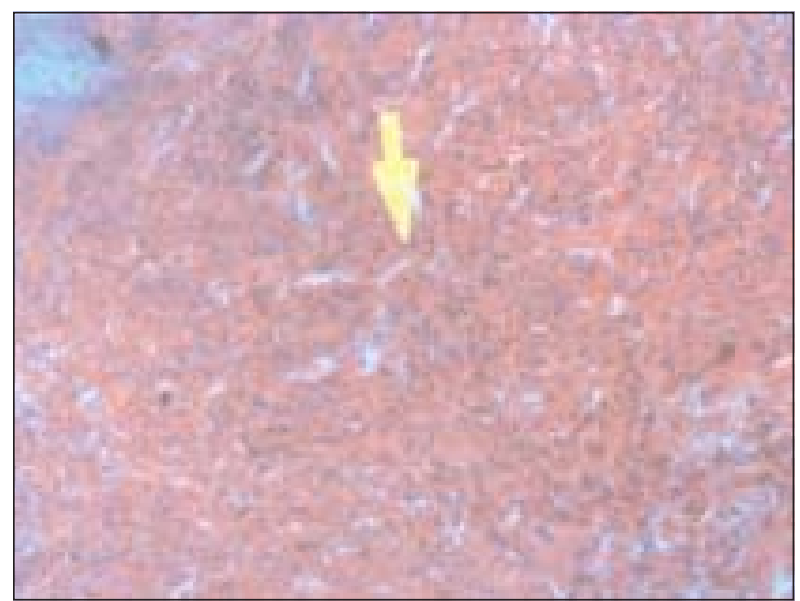

Fig.-3a: Frozen Preparation Shows Malignant cells.

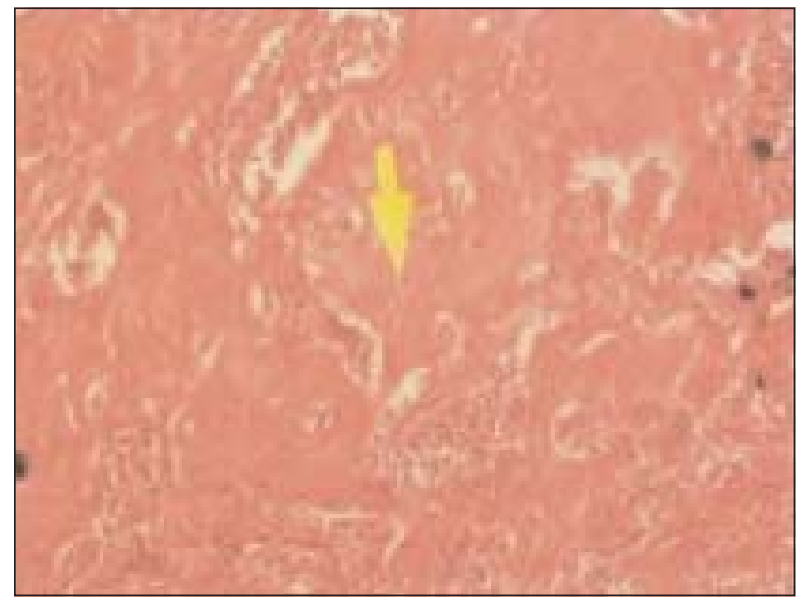

Fig.-3b: Paraffin Preparation of Same Sample Shows Malignant cells.

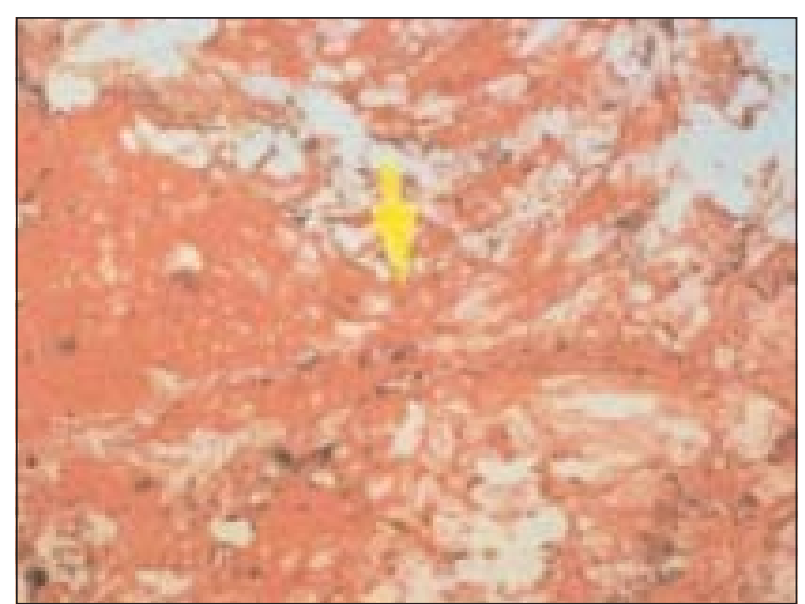

Fig.-4a: Frozen Preparation Shows Free of Malignant cells.

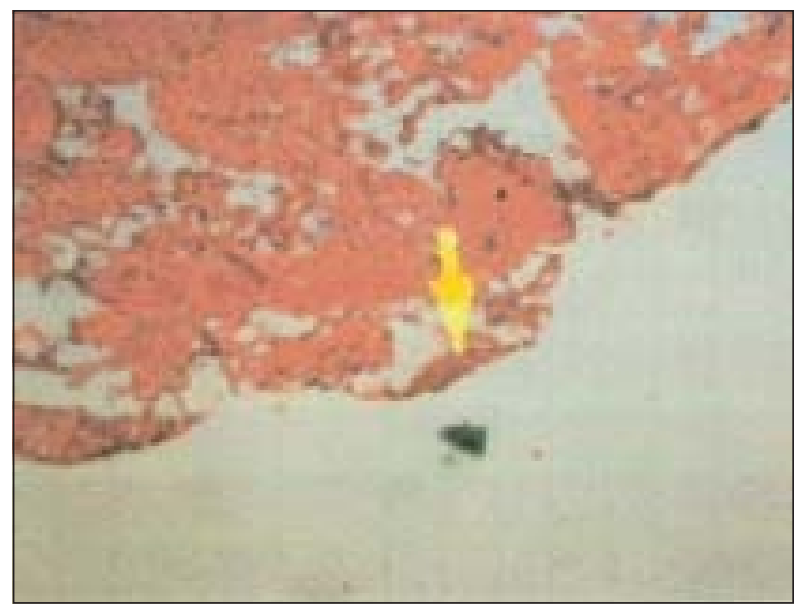

Fig.- 4b: Paraffin Preparation of Same Sample Shows Free of Malignant cells.

The specimen were subsequently processed for routine histopathological examination. All the sections were reviewed to compare frozen section and permanent section. Any discrepancies between the frozen and permanent section were mentioned in the histopathology report.

\section{Results}

The study included 29 patients out of which 17(58.6\%) were male and 12(41.4\%) were female and male female ratio was 1.4:1. The mean age of the study patients was $48.1 \pm 10.7$ years (mean $\pm \mathrm{SD}$ ). It was observed that majority of the patients belonged to 45 - 54 years age group. Regarding the socio economic status majority 18(62.1\%) were in the lower socio economic status and only $9(31.0 \%)$ were in the middle socio economic status. (Table I).

Table-I

Distribution of age, sex and socioeconomic status of the study subjects

\begin{tabular}{lccc}
\hline Parameters & No. of patients & Percent & Mean \pm SD \\
\hline Age & & & \\
$25-34$ & 2 & 6.9 & \\
$35-44$ & 9 & 31.0 & \\
$45-54$ & 11 & 37.9 & \\
$\quad 55$ and Above & 7 & 24.2 & \\
$\quad$ Total & 29 & 100.0 & $48.1 \pm 10.7$ \\
Sex & & & \\
$\quad$ Male & 17 & 58.6 & \\
$\quad$ Female & 12 & 41.4 & \\
$\quad$ Total & 29 & 100.0 & \\
Socioeconomic status & & & \\
$\quad$ Lower class & 18 & 62.1 & \\
$\quad$ Middle class & 9 & 31.0 & \\
$\quad$ Upper class & 2 & 6.9 & \\
\hline
\end{tabular}


In the present study, 111 margins from 29 patients were examined and average margin for each patient was 3.8. Out of which 32 (28.8\%) were positive and 79 (71.2\%) were negative (Table-II,III,IV). Among the total 32 positive margins of $1^{\text {st }}$ sample of 29 patients, 13 positive margins were re-examined by the second sample to ensure cancer free margin. Among these 13 positive margins on second FS sample, 5 margins were positive.

The patients were stratified solely by T-stage. In each Tstage group the total margins were higher in T3 which were 54 of 14 patients (mean 3.9) followed by T2, 40 of 10 patients (mean 4), T1, 9 of 2 patients (mean 4.5) and T4, 8 of 3 patients (mean 2.7). Positive margins with that of patients were $22.2 \%, 27.5 \%, 27.8 \%$ and $50.0 \%$ in $\mathrm{T} 1$, $\mathrm{T} 2$, T3 and T4 respectively. In this table, the number of the positive margins increased in relation to increased $\mathrm{T}$ stage. (Table-II).
Regarding the tumour grading of the patients, 48 total margins of 12 patients (mean 4) were found in grade I, out of which, 14 (29.2\%) were positive margins. In grade II, total margins were found 54 of 14 patients (mean 3.9), out of which, 15 (27.8\%) were positive margins. In grade III, total margins was found 9 of 3 patients (mean 3), out of which, 3(33.3\%) were positive margins. (Table-III).

The patients were classified in different stages of tumour. Total margins were 9 of 2 patients (mean 4.5) in stage I, out of which, 2(22.2\%) were positive margins. In stage II, total margins were 7 of 2 patients (mean 3.5), out of which, 2(28.6\%) were positive margins. In stage III total margins were 55 of 14 patients (mean 3.9), out of which, 16(29.1\%) were positive margins. In stage IV, total margins were 40 of 11 patients (mean 3.6), out of which, 12(30.0\%) were positive margins. In this table, the number of the positive margins increased in relation to increased stage (cTNM) of OSCC. (Table-IV).

Table-II

Status of surgical examined margins on the basis of T-stage (size of lesion) of OSCC

\begin{tabular}{|c|c|c|c|c|c|c|c|}
\hline \multirow{3}{*}{$\begin{array}{l}\text { T-status } \\
\text { (size of } \\
\text { lesion) }\end{array}$} & \multirow{3}{*}{$\begin{array}{c}\text { No. of } \\
\text { patients }\end{array}$} & \multirow{3}{*}{$\begin{array}{c}\text { Total } \\
\text { margins } \\
\text { examined } \\
n\end{array}$} & \multirow{3}{*}{$\begin{array}{l}\text { Average } \\
\text { margin } \\
\text { (mean) }\end{array}$} & \multicolumn{4}{|c|}{ Mean $1^{\text {st }}$ sample frozen section } \\
\hline & & & & \multicolumn{2}{|c|}{ +ve } & \multicolumn{2}{|c|}{-ve } \\
\hline & & & & $\mathrm{n}$ & $\%$ & $n$ & $\%$ \\
\hline $\mathrm{T}_{1}$ & 2 & 9 & 4.5 & 2 & 22.2 & 7 & 77.8 \\
\hline $\mathrm{T}_{2}$ & 10 & 40 & 4 & 11 & 27.5 & 29 & 72.5 \\
\hline $\mathrm{T}_{3}$ & 14 & 54 & 3.9 & 15 & 27.8 & 39 & 72.2 \\
\hline $\mathrm{T}_{4}$ & 3 & 8 & 2.7 & 4 & 50.0 & 4 & 50.0 \\
\hline Total & 29 & 111 & 3.8 & 32 & 28.8 & 79 & 71.2 \\
\hline
\end{tabular}

$\mathrm{T}_{1}:<2 \mathrm{~cm}, \mathrm{~T}_{2}: 2-4 \mathrm{~cm}, \mathrm{~T}_{3}:>4 \mathrm{~cm}, \mathrm{~T}_{4}:$ any size, involving adjacent structure, $\mathrm{n}=$ number

Table-III

Status of surgical examined margins on the basis of histopathological grading of OSCC.

\begin{tabular}{|c|c|c|c|c|c|c|c|}
\hline \multirow{3}{*}{$\begin{array}{l}\text { Tumour } \\
\text { grading }\end{array}$} & \multirow{3}{*}{$\begin{array}{c}\text { No. of } \\
\text { patients }\end{array}$} & \multirow{3}{*}{$\begin{array}{c}\text { Total } \\
\text { margins } \\
\text { examined } \\
\text { n }\end{array}$} & \multirow{3}{*}{$\begin{array}{l}\text { Average } \\
\text { margin } \\
\text { (mean) }\end{array}$} & \multicolumn{4}{|c|}{ Mean $1^{\text {st }}$ sample frozen section } \\
\hline & & & & \multicolumn{2}{|c|}{ +ve } & \multicolumn{2}{|c|}{-ve } \\
\hline & & & & $\mathrm{n}$ & $\%$ & $\mathrm{n}$ & $\%$ \\
\hline Grade-I & 12 & 48 & 4 & 14 & 29.2 & 34 & 70.8 \\
\hline Grade-II & 14 & 54 & 3.9 & 15 & 27.8 & 39 & 72.2 \\
\hline Grade-III & 3 & 9 & 3 & 3 & 33.3 & 6 & 66.7 \\
\hline Grade-IV & 0 & 0 & 0 & 0 & 0.0 & 0 & 0.0 \\
\hline Total & 29 & 111 & 3.8 & 32 & 28.8 & 79 & 71.2 \\
\hline
\end{tabular}


Table-IV

Status of surgical examined margins on the basis of stage (cTNM) of OSCC

\begin{tabular}{|c|c|c|c|c|c|c|c|}
\hline \multirow{3}{*}{$\begin{array}{l}\text { Stage of } \\
\text { tumour }\end{array}$} & \multirow{3}{*}{$\begin{array}{l}\text { No. of } \\
\text { patients }\end{array}$} & \multirow{3}{*}{$\begin{array}{c}\text { Total } \\
\text { margin examined } \\
\mathrm{n} \\
\end{array}$} & \multirow{3}{*}{$\begin{array}{c}\text { Average } \\
\text { margin (mean) }\end{array}$} & \multicolumn{4}{|c|}{ Mean $1^{\text {st }}$ sample frozen section } \\
\hline & & & & \multicolumn{2}{|c|}{ +ve } & \multicolumn{2}{|c|}{-ve } \\
\hline & & & & $\mathrm{n}$ & $\%$ & $\mathrm{n}$ & $\%$ \\
\hline I & 2 & 9 & 4.5 & 2 & 22.2 & 7 & 77.8 \\
\hline II & 2 & 7 & 3.5 & 2 & 28.6 & 5 & 71.4 \\
\hline III & 14 & 55 & 3.9 & 16 & 29.1 & 39 & 70.9 \\
\hline IV & 11 & 40 & 3.6 & 12 & 30.0 & 28 & 70.0 \\
\hline Total & 29 & 111 & 3.8 & 32 & 28.8 & 79 & 71.2 \\
\hline
\end{tabular}

\section{Discussion}

This cross sectional study was carried to achieve the tumour free surgical margin and also to cor-relate them with tumour size, grade and stage. This study was done in the Department of Oral and Maxillofacial Surgery and Department of Pathology, BSMMU during the period of January 2006 to December 2007.

A total 29 patients were enrolled in this study. Out of which, $58.6 \%$ were male and $41.4 \%$ were female. The malefemale ratio was $1.4: 1$. The mean age of the patients was $48.1 \pm 10.7$ years (mean \pm SD). Majority of the patients were in 45-54 years age group. Patients with known operable cases of oral squamous cell carcinoma were included. Some of the patient who received radiotherapy and chemotherapy were also included in this study.

Margins involved by carcinoma, carcinoma in situ, dysplasia, or with carcinoma within $5 \mathrm{~mm}$ were defined as positive. ${ }^{5}$ In present study, any tumour cell present within the $5 \mathrm{~mm}$ margins were regarded as positive.

In this present study, 111 margins from 29 patients were examined and average margin for each patient was 3.8. Out of which 32 (28.8\%) were positive and 79 (71.2\%) were negative (shown in table- II, III, IV). This result showed that the negative margins were comparatively greater than positive margins. In most of the studies, positive margins less than $30 \%$ in $1^{\text {st }}$ sample were acceptable. ${ }^{6,3,8}$ Among the total 32 positive margins of $1^{\text {st }}$ sample of 29 patients, 13 positive margins were reexamined by the second sample to ensure cancer free margin. Among these 13 positive margins on second FS sample, 5 margins were positive.

It has been noted that two forms of errors can occur in frozen section margin evaluation: interpretative and sampling errors. ${ }^{9}$ In this study, these type of errors were observed in 4 margins in 3 patients. Out of which, $0.9 \%$ was false positive and the rest $2.7 \%$ were false negative. The result indicated that the accuracy rate was $96.4 \%$ comparing frozen section to permanent section of the same tissues. Few researchers reported that comparing frozen section and paraffin section of the same tissue, the accuracy rate was between $96 \%$ and $99 \%{ }^{8}$ The study of these researchers closely matched with the present study.

It was observed in this study that the number of positive margins increased in relation to increase T-stage, which were $22.2 \%, 27.5 \%, 27.8 \%$ and $50 \%$ in $\mathrm{T}_{1}, \mathrm{~T}_{2}, \mathrm{~T}_{3}$ and $\mathrm{T}_{4}$ respectively. Loree and Strong reported that the number of positive margins was increased in relation to increased T-stage, which were $21 \%, 34 \%, 43 \%$ and $64 \%$ in $\mathrm{T}_{1}, \mathrm{~T}_{2}$, $\mathrm{T}_{3}$ and $\mathrm{T}_{4}$ respectively. ${ }^{3}$ So, this study support the present study.

Ord and Aisner reported that greater the stage (cTNM) greater the chance of getting positive margins in case of OSCC. ${ }^{6}$ In present study, the higher frequency of positive margins were in cTNM stage IV (30.0\%) followed by cTNM stage III (29.1\%), cTNM stage II (28.6\%) and cTNM stage I (22.2\%). The results indicates that the number of positive margins also increased in relation to increased cTNM stage, which is compatible with the study of Ord and Aisner. ${ }^{6}$

The percentage of positive margins were expected to increase with the increased grading of the tumour. But in this study it really did not follow the expectation.

A study on surgery vs surgery and radiotherapy reported that local recurrence rates were greater in patients with positive margins receiving radiotherapy than those of patients with negative margins not receiving postoperative radiotherapy. ${ }^{3}$ Adjuvant post-operative radiotherapy was also ineffective in local recurrence in the presence of positive margins. ${ }^{3}$ It is usually unacceptable and impractical to resect involved margins by a second surgical 
procedure. ${ }^{6}$ A complete excision must be obtained during per-operative surgery. Frozen section biopsy is best to ensure tumour free surgical margin and help to prevent recurrence. So one can easily realize the usefulness of frozen section biopsy.

\section{Conclusion}

the intra-operative frozen biopsy helps to achieve tumour free surgical margin in the resection of oral squamous cell carcinoma. In this study, it was also observed that the number of positive margins increased in relation to increased tumour size and tumour stage (cTNM).

\section{Acknowledgement}

We greatly acknowledge the contribution of Professor Dr. Mohammed Kamal, Associate Prof. Tamanna Chowdhury, Dr. Mahmudul Huda and other residents of pathology department, BSMMU. We also like to extend sincere thanks to Associate Prof. Quazi Billur Rahman, Dr. Rakibul Hasan Murad, Dr. Supriya Roy and my other departmental colleagues of Oral and Maxillofacial Surgery, BSMMU. Last not least, we are gratefull those patients who were involved in this study.

\section{References}

1. Jaafar H. Intra-operative frozen section consultation: concepts, applications and limitations. Malaysian Journal of Medical Sciences 2006; 13: 4-12.
2. Shaheed I, Hossain A, Molla MR. Histological and causative factor of oral cancer in Bangladesh. Oral Oncology; Applied. Proceedings of the $4^{\text {th }}$ international congress on oral cancer. Ogaki city, Japan. 1995; 4: 27-30.

3. Loree TR, Strong EW. Significance of positive margins in oral cavity squamous carcinoma. Am J Surg 1990; 160: 110-14.

4. Ribeiro NF, Godden DR, Wilson GE. Do frozen sections help achieve adequate surgical margins of the resection of oral carcinoma? Int.J. Oral Maxillofac Surg 2003; 32: 152-58.

5. Gooris PJ, Visscher JG, Roodenburg JL. Frozen section examination of the margins of resection of squamous cell carcinoma of the lower lip. J Oral Maxillofac Surg 2003; 61: 890-94.

6. Ord RA, Aisner S. Accuracy of frozen sections in assessing margins in oral cancer resection. J Oral Maxillofac Surg. 1997; 55: 66368.

7. Frable WJ. Accuracy of frozen sections in assessing margins in oral cancer resection: Discussion. J Oral Maxillofac Surg 1997; 55: 663-66.

8. Dinardo LJ, Lin J, Karageorge LS et al. Accuracy, utility, and cost of frozen section margins in head and neck cancer surgery. Laryngoscope 2000; 110: 1973-77.

9. Gandour-Edwards R, Donald PJ, Wiese D. The accuracy and clinical utility of frozen section diagnosis in head and neck surgery. Experience at a university medical centre. Head Neck 1993; 15: 33-38. 